Fifth International Conference on Sustainable Construction Materials and

Technologies. http://www.claisse.info/Proceedings.htm

\title{
PRELIMINARY STUDIES OF SUSTAINABLE CONCRETE INCORPORATING CERAMIC HYBRID BINDERS
}

\author{
Amir AlArab', Bilal Hamad², and Ghassan Chehab ${ }^{3}$ \\ ${ }^{1}$ Graduate Student, Department of Civil and Environmental Engineering, American \\ University of Beirut, PO Box 11-0236 Riad ElSolh 1107-2020; Email: \\ ara35@mail.aub.edu \\ ${ }^{2}$ Professor, Department of Civil and Environmental Engineering, American University \\ of Beirut; PO Box 11-0236 Riad ElSolh 1107-2020, Tel.: +961 333580, Email: \\ bhamad@aub.edu.lb \\ ${ }^{3}$ Associate Professor, Department of Civil and Environmental Engineering, American \\ University of Beirut, PO Box 11-0236 Riad ElSolh 1107-2020, Email: \\ gc06@aub.edu.lb
}

\begin{abstract}
Concrete incorporating ceramic hybrid binder is a sustainable concrete material prepared by partial replacement of Portland cement with a proper dosage of ceramic powder and mineral admixtures. Reported research indicates that partial replacement of Portland cement with ceramic powder decreases the mechanical strength properties of concrete. The objective of the research reported in this paper was to check whether the negative impact of ceramic powder incorporated in the concrete mix could be reduced if pozzolanic materials such as slag cement are also included. Concrete batches were prepared with Portland cement and ceramic hybrid binders incorporating different combinations of ground ceramic powder and slag cement. Tests on the different batches included compressive strength, splitting tensile strength, flexural strength, and modulus of elasticity. The objective was to find a sustainable concrete material while recycling and reusing ceramic wastes without any negative impact on the hardened mechanical properties.
\end{abstract}

Keywords: sustainable concrete; ceramic powder; pozzolanic material; hardened concrete properties.

\section{INTRODUCTION AND BACKGROUND}

Ceramic is one of the most ancient fabricated products on earth. According to the American Ceramic Society, De Guire (2014) stated that ceramic production started 
initially by firing slurry which is a semiliquid clayey material. Ceramic manufacturing techniques improved with time involving different products such as high-temperature resistance ceramic, electrical insulators, and other modern features that made the product a technical ceramic that has many forms, usages, and properties nowadays.

The raw materials of ceramic are feldspar, quartz, ball clay and talc powder. Worral (1982) specified that 95\% of feldspar consumption is for ceramic production. Feldspar plays an important role as a flux in the ceramic green mix. When ceramic raw materials are heated at high temperature $\left(1250-1400^{\circ} \mathrm{C}\right)$, feldspar accelerates the melting of quartz at a lower temperature, whereas quartz and clay are acknowledged for the strength, composition, and plasticity of ceramics and talc powder works as a filler in the mix. Numerous studies have explored the behavior of ceramic powder as a cement replacement in concrete (Naceri and Hamina 2009; Vejmelková et al. 2012; Heidari and Tavakoli 2013; Raval et al. 2015; Subas and Emirog 2017). In these studies, scholars revealed that the ceramic powder reduced the compressive strength of concrete at early days however the deficiency in strength was reduced with time yet the strength did not reach that of the conventional concrete. In addition, several articles classified the ceramic as a pozzolanic material based on microstructure characterization and chemical testing (Naceri and Hamina 2009; Steiner et al. 2015; Patel et al. 2015; Kannan et al. 2017).

Raval et al. (2013) and Vejmelková et al. (2012) revealed that the incorporation of 20\% ceramic powder as cement substitute was considered the limit where subsequently the compressive strength dropped dramatically. Subas and Emirog (2017) showed that the addition up to $15 \%$ of ceramic had an insignificant effect on the flexural capacity. Heidari and Tavakoli (2013) tried to improve the performance of the concrete containing ceramic using Nano-silica. They found that the addition of 10\% and 20\% ceramic powder as cement replacement led to decrease in the compressive strength of the concrete estimated by 9 and $16 \%$ at 28 days. Adding 1\% Nano-silica as an additive to the $10 \%$ and $20 \%$ ceramic concrete mixes was very effective in improving the compressive strength in the range of 3 and $11 \%$ improvements compared to the conventional concrete.

\section{RESEARCH OBJECTIVE AND SCOPE}

The objective of the study is to identify a sustainable concrete material based on recycling and reusing ceramic wastes without any negative impact on the hardened mechanical properties such as compressive and flexural capacities. Research reported in the literature indicates that replacing percentages of Portland cement in concrete with ceramic powder decreases the mechanical strength properties of concrete. It was important to check if such reduction could be surpassed by replacing cement with hybrid powder made of ceramic powder and slag cement. The experimental program aims at exploring the behavior of the new hybrid material composed of ceramic and slag cement. The objective was achieved by assessing the mechanical properties of the hybrid concrete batches by conducting the following tests: compressive strength, splitting tensile strength, flexural strength, and modulus of elasticity. 


\section{MATERIALS}

A hybrid binder of the concrete was prepared using ceramic powder and slag cement. In other words, the hybrid binder will be formed using different percentages of ceramic powder with slag cement powder, to replace Portland cement. Ceramic is commonly used in tiling works and is classified into many types one of which is the porcelain type which was used in this study. The ceramic powder was prepared using a bico pulverizer grinder machine and the output was then sieved through \#200. The cement utilized was PL42.5, in compliance with the EN 197 European norms (CEM II (A-L). The maximum aggregate size of the coarse aggregate used was $19 \mathrm{~mm}$ and the fineness modulus of the fine aggregate was 3.0. The bulk specific gravities for the coarse and fine aggregates were 2.68 and 2.64, respectively. The absorption capacities for coarse and fine aggregates were $1.74 \%$ and $0.6 \%$, respectively. The slag type used had similar fineness as cement.

\section{EXPERIMENTAL PROGRAM}

Concrete batches were prepared using Portland cement and ceramic hybrid binders formed by integrating different percentages of Porcelain ceramic powder $(0,10,15$ and $20 \%$ ) as well as slag powder (40\% of cement content). The choice of these ceramic percentage replacements was based on the results of the published literature that showed that the adequate ceramic replacements ranged between $10 \%$ and $20 \%$.

\section{Mix Design}

The mixes were designed in accordance with the ACI guidelines (ACI 211.1) to achieve an intended compressive strength of $30 \mathrm{MPa}$. The only variable is the inclusion of sustainable materials as a cement substitute where the percentage replacement of cement by sustainable materials is by weight. Table 1 represents the dry weight proportioning of the four mixes selected in this study.

Table 1. Mix proportions

\begin{tabular}{|l|c|c|c|c|c|c|c|}
\hline $\begin{array}{l}\text { Mix } \\
\text { Proportions }\end{array}$ & $\begin{array}{c}\text { Water } \\
(\mathrm{Kg})\end{array}$ & $\begin{array}{c}\text { Cement } \\
(\mathrm{Kg})\end{array}$ & $\begin{array}{c}\text { Slag } \\
(\mathrm{Kg})\end{array}$ & $\begin{array}{c}\text { Ceramic } \\
(\mathrm{Kg})\end{array}$ & $\begin{array}{c}\text { Coarse } \\
\text { Agg. } \\
(\mathrm{Kg})\end{array}$ & $\begin{array}{c}\text { Fine } \\
\text { Agg. } \\
(\mathrm{Kg})\end{array}$ & $\begin{array}{c}\mathrm{NN} \\
(\mathrm{Kg})\end{array}$ \\
\hline Control & 200 & 370 & 0 & 0 & 991 & 807 & 2.2 \\
\hline $40 \mathrm{~S}-10 \mathrm{Cr} *$ & 200 & 200 & 133 & 37 & 991 & 807 & 2.2 \\
\hline $40 \mathrm{~S}-15 \mathrm{Cr}$ & 200 & 188.7 & 125.8 & 55.5 & 991 & 807 & 2.2 \\
\hline $40 \mathrm{~S}-20 \mathrm{Cr}$ & 200 & 177.6 & 118.4 & 74 & 991 & 807 & 2.2 \\
\hline
\end{tabular}

40S-10Cr implies that slag is 40\% of cement content and that ceramic replaces $10 \%$ of pozzolanic powder.

\section{Testing Program}

The testing program consists of the following mechanical tests: compressive strength, splitting tensile strength, flexural strength, and modulus of elasticity. Samples 
were tested at different curing time intervals (7, 28 and 56 days) to assess the effect of time on the mechanical properties of the cementitious material. It is important to mention that samples were cured prior to testing in water tanks. Geometry of specimens used in each test is shown in Table 2.

Table 2. Testing program

\begin{tabular}{llccc}
\hline Hardened Concrete & \multicolumn{1}{c}{$\begin{array}{c}\text { Dimensions } \\
\text { Testing }\end{array}$} & \multicolumn{1}{c}{ No. of Specimens } \\
\cline { 3 - 5 } & & $\begin{array}{c}7 \\
\text { Days }\end{array}$ & 28 Days & 56 Days \\
Compressive Strength & Cylinder 10x20 & 3 & 3 & 3 \\
\hline Split tensile Strength & Cylinder 10x20 & - & 3 & 3 \\
\hline Modulus of Elasticity & Cylinder 15x30 & - & 3 & 3 \\
\hline Flexure Capacity & $\begin{array}{l}\text { Beam } \\
\text { 10x10x35 }\end{array}$ & - & 3 & 3 \\
\hline
\end{tabular}

\section{Compressive Strength Test}

The compressive strength of the cylindrical concrete specimens was estimated in accordance with ASTM C39. In this test method, a compressive axial load is applied to the specimen at a rate of $1.25 \mathrm{~mm} / \mathrm{min}$ until failure occurs as shown in Figure 1 . Capping the samples prior to testing is essential to ensure a uniform distribution of the load along the surface.

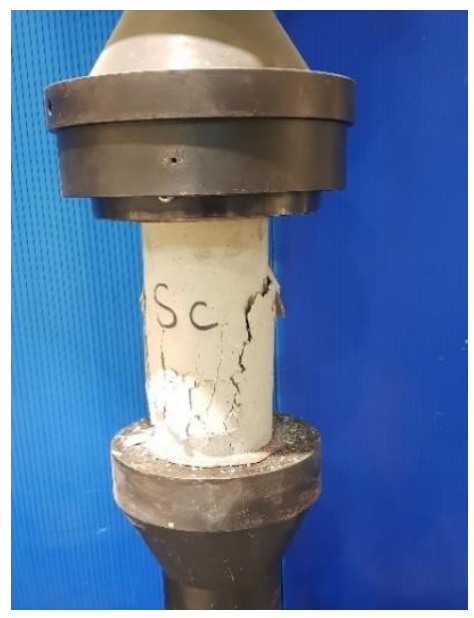

Figure 1. Compressive strength test setup

\section{Splitting Tensile Test}

The splitting tensile strength of $10 \times 20 \mathrm{~cm}$ cylinders for the three series was determined, according to ASTM C496 using the YLS testing machine with a capacity of 50 Tons. The test setup shown in Figure 2 consists of placing a specimen between 2 metal plates (top and bottom) of $4 \mathrm{~mm}$ thickness. The plates will restrain the movement of the loaded specimen. The loading rate was set to $2 \mathrm{~mm} / \mathrm{min}$. 


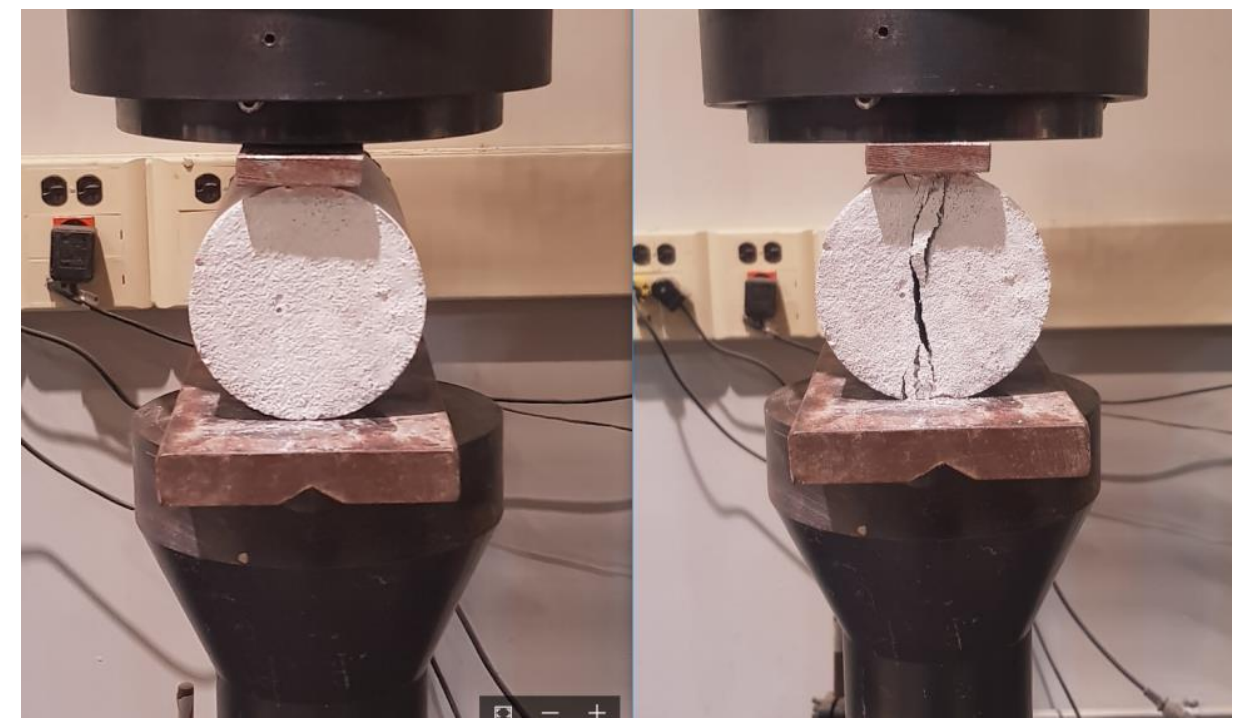

Figure 2. Split tensile test

\section{Flexure Capacity Test}

The flexural response of $100 \times 100 \times 350 \mathrm{~mm}$ beams under a third-point loading was determined by modulus of rupture in accordance with ASTM C78. The beam was supported by two rollers located at $25 \mathrm{~mm}$ from the concrete edges as illustrated by Figure 3. A loading plate with $100 \mathrm{~mm}$ spacing was set in a way that the clear span of the beams is divided to three equal distances of $100 \mathrm{~mm}$ each. LVDT was set at midspan in the bottom of the specimen to measure the deflection at mid-span of the specimens. Beams were loaded under a displacement-controlled rate of $1 \mathrm{~mm} / \mathrm{min}$.

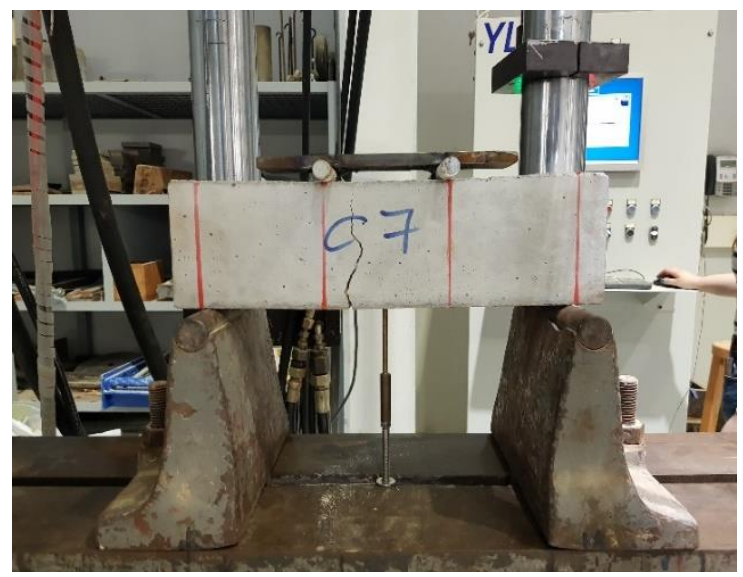

Figure 3. Flexural capacity test Setup 


\section{Modulus of Elasticity}

The Modulus of Elasticity of the concrete was determined in accordance to ASTM C469. The cylindrical concrete samples have the following dimension $150 \times 300 \mathrm{~mm}^{2}$. The test was conducted in the MTS machine of 300 Tons capacity and was controlled by displacement with a rate of $1.5 \mathrm{~mm} / \mathrm{min}$. The axial deformation was measured through a dial gauge. The MOE setup is shown in Figure 4.

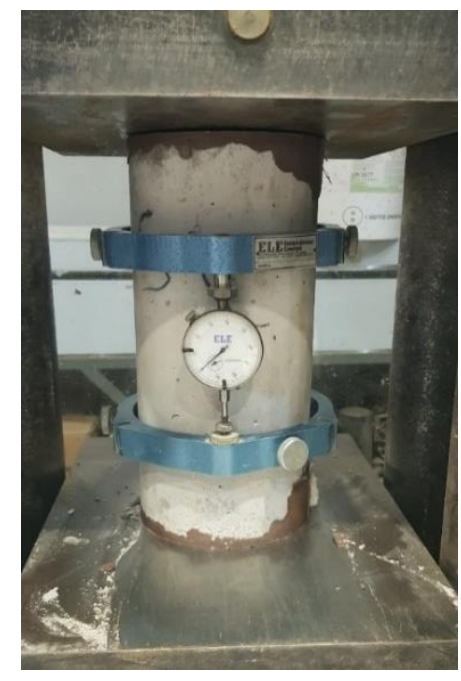

Figure 4. MOE test setup

\section{TEST RESULTS AND ANALYSIS}

The test results are presented in Figures 5 to 8 and in Tables 3 to 6 . This section includes an examination of the mechanical properties of the hybrid concrete. The compressive strength, splitting tensile strength, flexural strength, and modulus of elasticity results are presented and discussed.

\section{Compressive Strength Test Results}

Figure 5 shows the compressive strength results (7,28, 56 days) of the 3 mixes made with slag cement (with slag is $40 \%$ of cement content) and the three ceramic percentages $10 \% 15 \%$, and $20 \%$, as well as the control concrete mix which is made only of cement. With reference to Table 3 , it can be observed that the hybrid powder attributed in lowering the compressive strength at 7 days where the strength dropped by 17,23 , and $32 \%$ for the three mixes $40 \mathrm{~S}-10 \mathrm{Cr}, 40 \mathrm{~S}-15 \mathrm{Cr}$, and $40 \mathrm{~S}-20 \mathrm{Cr}$, respectively. At 28 days, the reductions in strength were 5, 18, and 30\%, respectively. 
As for the 56 days, the $40 \mathrm{~S}-10 \mathrm{Cr}$ mix showed an improvement of $4 \%$ as compared with the control whereas the $40 \mathrm{~S}-15 \mathrm{Cr}$ mix had almost a slight reduction of $7 \%$.

Table 3. Ratios of compressive strength values to that of the control mix

\begin{tabular}{lccc}
\hline Testing Date & S40-Cr10 & S40-Cr15 & S40-Cr20 \\
\hline 7 Days & $-17 \%$ & $-23 \%$ & $-32 \%$ \\
\hline 28 Days & $-5 \%$ & $-18 \%$ & $-30 \%$ \\
\hline 56 Days & $4 \%$ & $-7 \%$ & $-19 \%$ \\
\hline
\end{tabular}

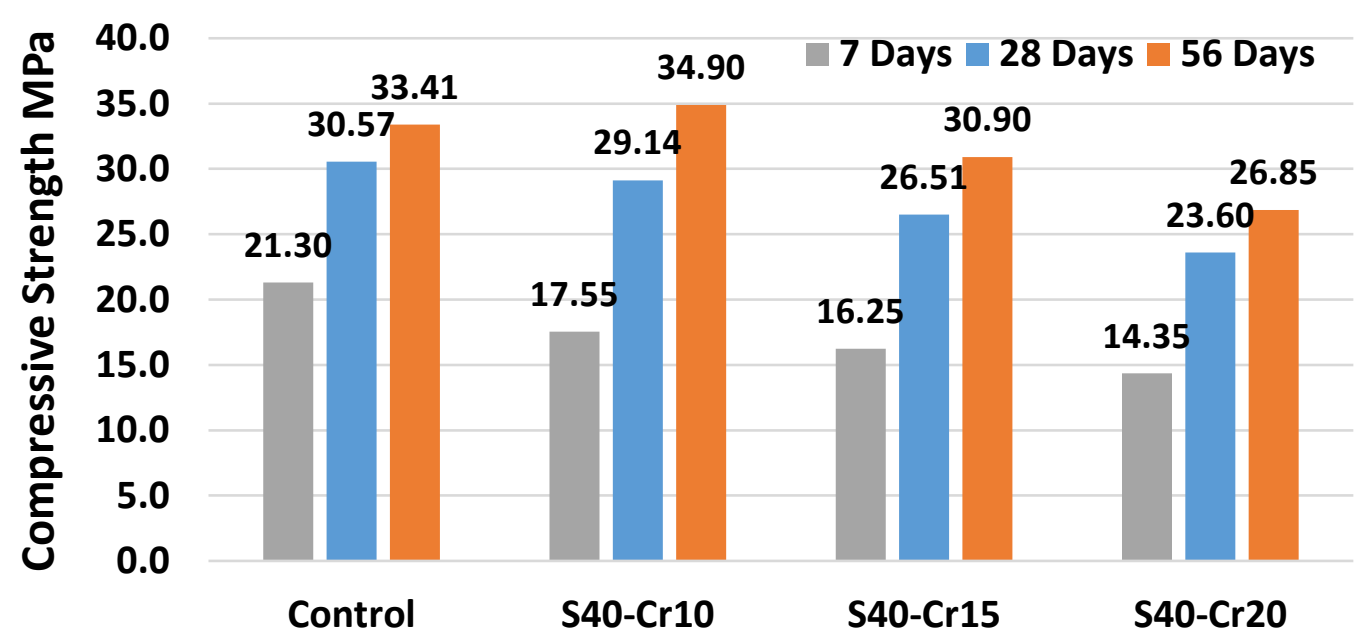

Figure 5. Compressive strength results

\section{Splitting Tensile Test Results}

The splitting tensile strength results at 28 and 56 days are presented in Figure 6. At 28 days the hybrid binder had an insignificant effect on the splitting tensile strength where the tensile strength values for the four mixes ranged between 2.57 and 2.66. With reference to Table 4, the 56 days test results revealed that the S40-Cr10 and S40-Cr15 mixes showed a slight improvement in the strength of about 9 and $6 \%$, respectively. In contrast, the S40-Cr20 mix indicated a reduction of $6 \%$ in the splitting tensile strength. 


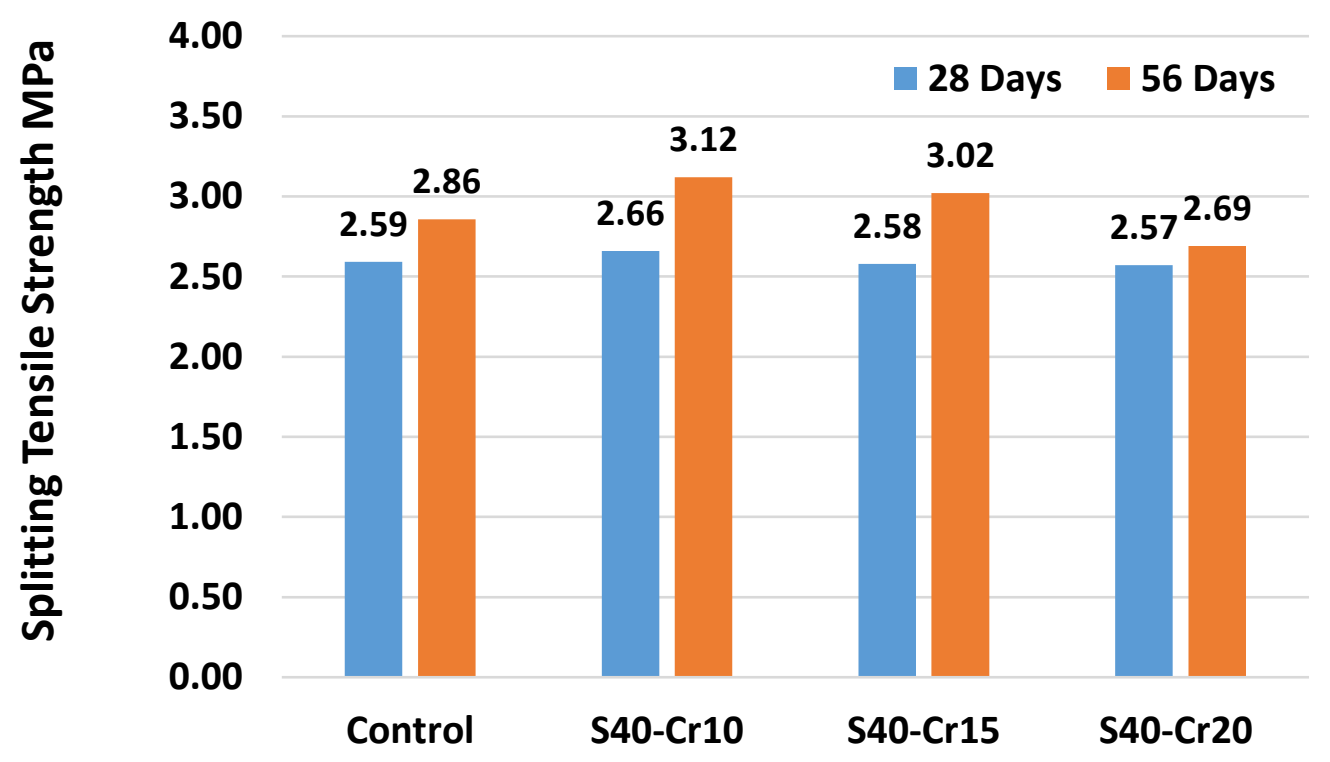

Figure 6. Splitting tensile strength results

Table 4. Ratios of splitting tensile strength values to that of the control mix

\begin{tabular}{lccc}
\hline Testing Date & S40-Cr10 & S40-Cr15 & S40-Cr20 \\
\hline 28 Days & $3 \%$ & $0 \%$ & $-1 \%$ \\
\hline 56 Days & $9 \%$ & $6 \%$ & $-6 \%$ \\
\hline
\end{tabular}

\section{Flexure Capacity Test Results}

The flexure capacity for the specimens tested at 28 and 56 days are shown in Figure 7. With reference to Table 5, the flexural strength test at 28 days revealed that the usage of the hybrid powders led to a reduction in the flexural capacity in the order of $10,2 \%$, and $2 \%$ for the three mixes S40-Cr10, S40-Cr15, S40-Cr20, respectively. This reduction turned into improvement in the flexural capacity at 56 days of about $6 \%$, $16 \%$, and 5\% for the mixes S40-Cr10, S40-Cr15, S40-Cr20, respectively. 


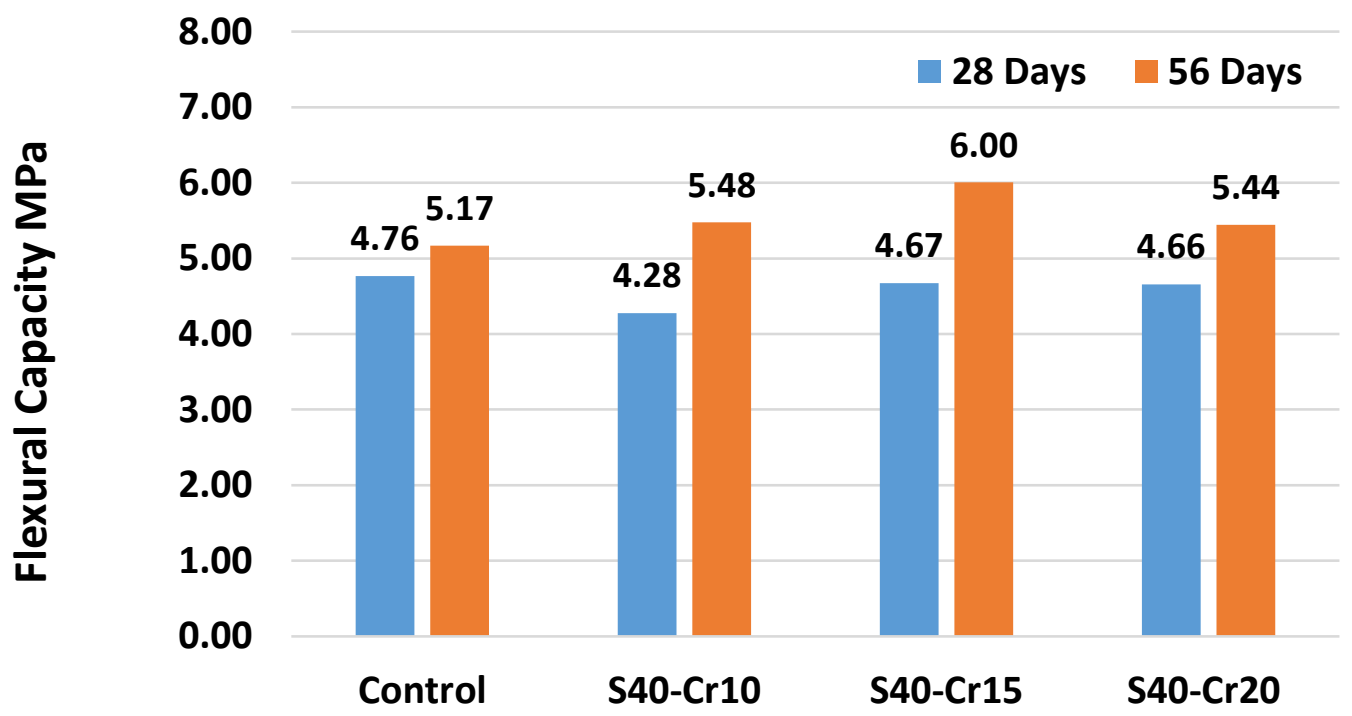

Figure 7. Flexural capacity results

Table 5. Ratios of flexural capacity values to that of the control mix Drop and gain in flexure capacity

\begin{tabular}{lccc} 
Testing Date & S40-Cr10 & S40-Cr15 & S40-Cr20 \\
\hline 28 Days & $-10 \%$ & $-2 \%$ & $-2 \%$ \\
\hline 56 Days & $6 \%$ & $16 \%$ & $5 \%$ \\
\hline
\end{tabular}

\section{Modulus of Elasticity Test Results}

The modulus of elasticity for the specimens tested at 28 and 56 days are shown in Figure 8. With reference to Figure 8 and Table 6 , the modulus of elasticity test results indicated that the S40-Cr10 mix had the highest modulus of elasticity among all the other mixes at both 28 and 56 days of about $17.8 \mathrm{MPa}$ at 28 days and $21.2 \mathrm{MPa}$ at 56 days. In contrast, the S40-Cr15 and S40-Cr20 mixes led to a decrease in the modulus of elasticity at both studied curing ages. 
25.0

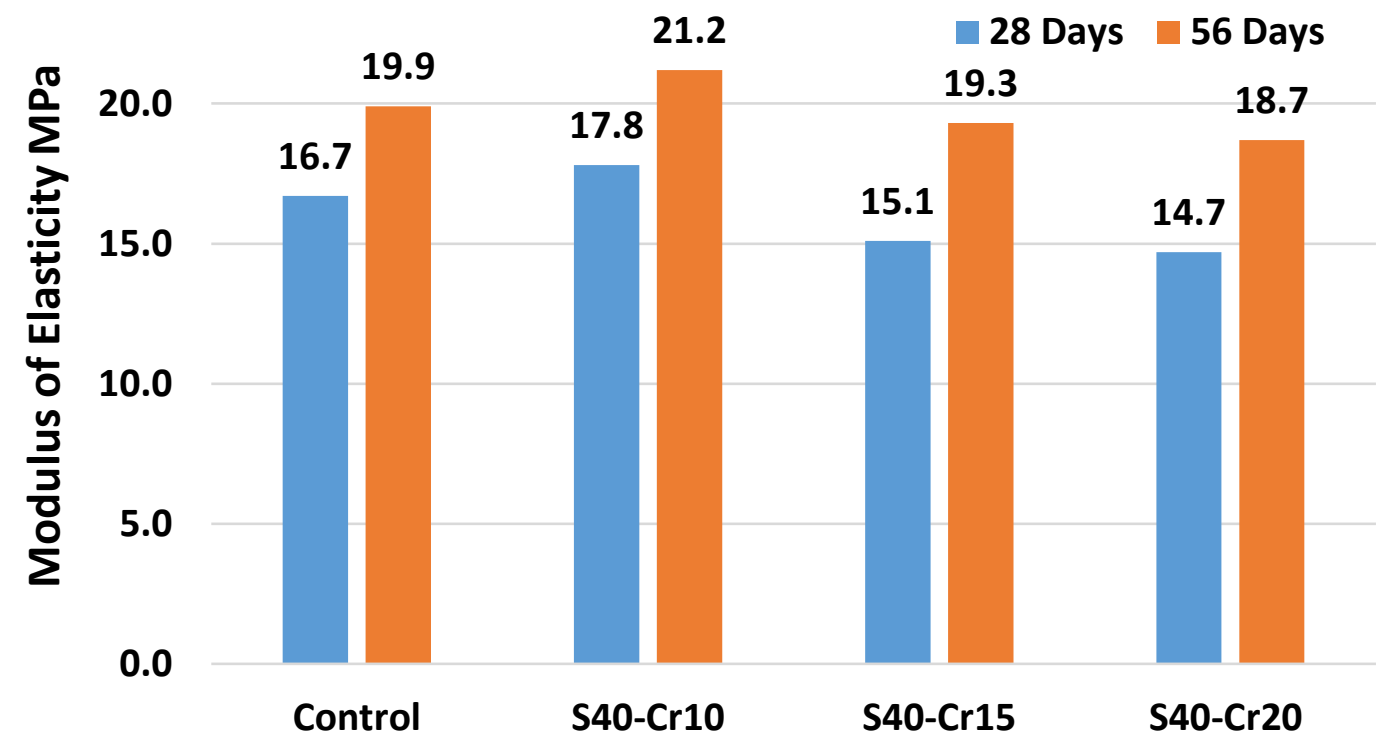

Figure 8. Modulus of elasticity test results

Table 6. Ratios of modulus of elasticity values to that of the control mix

\begin{tabular}{lccc}
\hline Testing Date & S40-Cr10 & S40-Cr15 & S40-Cr20 \\
\hline 28 Days & $7 \%$ & $-10 \%$ & $-12 \%$ \\
\hline 56 Days & $7 \%$ & $-3 \%$ & $-6 \%$ \\
\hline
\end{tabular}

\section{CONCLUSIONS}

Based on the results of the experimental plan conducted in this study, the following conclusions could be drawn:

1. The hybrid concrete made of $10 \%$ ceramic and slag cement was able to maintain the compressive strength of concrete at the late age of 56 days. As for the early ages, the hybrid concrete showed lower compressive strength.

2. The modulus of elasticity results were consistent with the compressive strength results where the hybrid mix with $10 \%$ Ceramic content led to the highest modulus of elasticity.

3. The hybrid powder had almost no effect on the splitting tensile strength.

4. The hybrid mix with $15 \%$ ceramic led to the highest flexural capacity.

5. The hybrid powder made of $36 \%$ slag, $10 \%$ ceramic, and $54 \%$ cement has a great potential to be used as a cement replacement with insignificant negative effect on the mechanical properties. 


\section{REFERENCES}

ACI, A. (2002). 211.1-Standard Practice for Selecting Proportions for Normal. Heavyweight, and Mass Concrete.

ASTM C496 Standard Test Method for Splitting Tensile Strength of Cylindrical Concrete Specimens

ASTM C78 Standard Test Method for Flexural Strength of Concrete (Using Simple Beam with Third-Point Loading)

ASTM C39 Standard Test Method for Compressive Strength of Cylindrical Concrete Specimens

De Guire, E. (2014). History of Ceramics. The American Ceramic Society, 19.

Heidari, A., \& Tavakoli, D. (2013). A study of the mechanical properties of ground ceramic powder concrete incorporating nano- $\mathrm{SiO}_{2}$ particles. Construction and Building Materials, 38, 255-264. https://doi.org/10.1016/j.conbuildmat.2012.07.110

Kannan, D. M., Aboubakr, S. H., El-Dieb, A. S., \& Taha, M. M. R. (2017). High performance concrete incorporating ceramic waste powder as large partial replacement of Portland cement. Construction and Building Materials, 144, 3541.

Naceri, A., \& Hamina, M. C. (2009). Use of waste brick as a partial replacement of cement in mortar. Waste management, 29(8), 2378-2384.

Patel, H., Collage, L. E., \& Vaniya, S. R. (2015). Use of Ceramic Waste Powder in Cement Concrete. International Journal for Innovative Research in Science \& Technology, 2(1), 91-97.

Raval, A. D., Patel, I. N., \& Pitroda, P. J. (2015). Ceramic Waste: Effective Replacement of Cement for Establishing Sustainable Concrete Ceramic Waste. International Journal of Engineering Trends and Technology (IJETT), 4(6), 2324-2329.

Steiner, L. R., Bernardin, A. M., \& Pelisser, F. (2015). Effectiveness of ceramic tile polishing residues as supplementary cementitious materials for cement mortars. Sustainable Materials and Technologies, 4, 30-35.

Subas, S., \& Emirog, M. (2017). Utilizing of waste ceramic powders as filler material in self-consolidating concrete. Construction and Building Materials, 149, 567574. https://doi.org/10.1016/j.conbuildmat.2017.05.180

Vejmelková, E., Keppert, M., Rovnaníková, P., Ondrác, M., \& Robert, C. (2012). Cement \& Concrete Composites Properties of high performance concrete containing fine-ground ceramics as supplementary cementitious material. Cement \& Concrete Composites, 34, 55-61. https://doi.org/10.1016/j.cemconcomp.2011.09.018

Vejmelková, E., Keppert, M., Rovnaníková, P., Ondráček, M., Keršner, Z., \& Černý, R. (2012). Properties of high performance concrete containing fine-ground 
ceramics as supplementary cementitious material. Cement and Concrete Composites, 34(1), 55-61.

Worral, W. E. (1982). Ceramic raw materials. Institute of Ceramics Textbook Series. 